\title{
Design, Performance Evaluation and Field Test of a Water Jet Tool for ROV Trencher
}

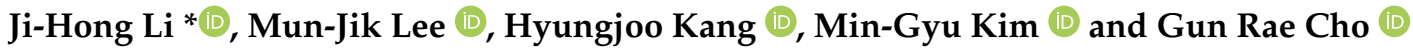 \\ Intelligent Robotics R\&D Division, Korea Institute of Robotics and Technology Convergence, Jigok-Ro 39, \\ Nam-Gu, Pohang 37666, Korea; mcklee@kiro.re.kr (M.-J.L.); hjkang@kiro.re.kr (H.K.); \\ zxdwa0817@kiro.re.kr (M.-G.K.); sandman@kiro.re.kr (G.R.C.) \\ * Correspondence: jhli5@kiro.re.kr; Tel.: +82-54-279-0467
}

check for updates

Citation: Li, J.-H.; Lee, M.-J.; Kang, H.; Kim, M.-G.; Cho, G.R. Design, Performance Evaluation and Field Test of a Water Jet Tool for ROV Trencher. J. Mar. Sci. Eng. 2021, 9, 296. https://doi.org/10.3390/ jmse9030296

Academic Editor: Simone Mancini

Received: 2 February 2021

Accepted: 28 February 2021

Published: 8 March 2021

Publisher's Note: MDPI stays neutral with regard to jurisdictional claims in published maps and institutional affiliations.

Copyright: (c) 2021 by the authors. Licensee MDPI, Basel, Switzerland. This article is an open access article distributed under the terms and conditions of the Creative Commons Attribution (CC BY) license (https:/ / creativecommons.org/licenses/by/ $4.0 /)$.

\begin{abstract}
ROV trencher is a kind of ROV which trenches the sea floor using a specifically designed tool and buries the subsea cables and pipelines. According to the soil conditions, this trenching method can have two different types, one is mechanical cutting and the other one is water jetting. In this paper, we present a water jet tool design method for a $2500 \mathrm{~m}$ depth-rated ROV trencher. A series of CFD simulations and laboratory tests with one nozzle, and a ground test using 1:6 scale jetting arm model were carried out to derive and demonstrate the jetting tool design parameters. In October 2018, the constructed ROV trencher was put into the sea trial in the East Sea of Korea to evaluate its final performances. In addition, in December 2019, the trencher was applied in a construction site to bury subsea water pipelines near the Yogji Island in the Korea. Through these two field tests and operation, the trencher was demonstrated for both its operational capability and trenching performance. The main contribution of this paper is that it presents the entire design procedures of water jet tools, including CFD simulations, laboratory tests, field test with 1:6 scaled jetting tool, and the final prototype tool design. These consecutive procedures are carried out in order for us to set up sort of relationship between jetting angle, trench depth, trench speed, and jetting power, from which we can predict and evaluate the trenching performance of the prototype jetting tool.
\end{abstract}

Keywords: ROV trencher; subsea cable and pipeline burying; water jetting arm; Froude number; trench depth; trench speed

\section{Introduction}

Driven by economic and social development in the past decades, there have been ever growing needs for various subsea cables and pipelines connecting land, islands, ocean plants, and even continents. In the beginning, these subsea cables and pipelines were simply laid on the seafloor. However, due to the increase of fishing activities (including trawl net fishing) as well as other dangerous human activities in the ocean, it is strongly recommended that subsea cables and pipelines be buried under the seafloor [1]. Usually, there are two types of subsea cable and pipeline burying methods. One is the simultaneous lay and burial method, and the towed plough is usually applied for this end. After this plough operation, the cable should be inspected for conformity with the specifications. In addition, there are some circumstances where the plough cannot be operated (e.g., where the cable is in close proximity to another cable). In both cases, it might need the second burial method called PLIB (post lay inspection and burial). The ROV trencher is the most feasible tool to carry out this kind of operation.

According to the different soil conditions, there are usually two different types of trenching methods: one is mechanical cutting and the other one is water jetting [2]. The water jetting method is optimized in the case of soil conditions from $5 \mathrm{kPa}$ to $100 \mathrm{kPa}$. For this type of ROV trencher, there are a pair of water jetting arms (also called as jet leg or sword) - each of them symmetrically (right and left) mounted at the bottom of platform. 
When they are deployed by hydraulic cylinders, these two arms straddle the previously laid cable or pipeline, and jet the water through the nozzles mounted on the arms and cut a trench and bury the cable or pipeline. From this point of view, in addition to the water pump specifications, the jetting arms configuration including nozzle dimensions and their arrangement directly affects the trenching performance. This paper presents the water jet tool design method and procedure in the development of a $2500 \mathrm{~m}$ depth-rated ROV trencher [3], whose required specifications are as shown in Table 1.

Table 1. ROV trencher required specifications.

\begin{tabular}{lll}
\hline ROV Trencher & Items & Specifications \\
\hline & Depth rating & $\begin{array}{l}2500 \mathrm{~m} \\
\text { Trench depth }\end{array}$ \\
Trench speed & $\begin{array}{l}\text { Max. } 2 \mathrm{~km} / \mathrm{h} \text { with } \leq 40 \mathrm{kPa} \text { sand soil } \\
\leq 40 \mathrm{kPa} \text { soil type }\end{array}$ \\
\end{tabular}

Due to the variety of seafloor soil types, it is difficult, if not impossible, to design an optimal water jet tool. Nevertheless, we have followed a series of design procedures including CFD simulation studies and performance verifications through both laboratory and field tests. For given jetting arm length and jetting power, other jetting arm design parameters (such as jetting nozzle diameter, number, and jetting angle) were tuned through investigating the jetting power transmission length in the CFD simulation. On the other hand, laboratory experiments with one nozzle and sand soil laid in a glass wall tank, which is similar to the setups in the [4-7], were carried out to investigate the relationships between jetting angle, traverse rate, trenching depth, and jetting power. Experiment results showed that the designed nozzle number and given water pump power can guarantee the $2 \mathrm{~km} / \mathrm{h}$ of trenching speed with each nozzle trenching depth exceeding $0.3 \mathrm{~m}$. After these design processes, we constructed a 1:6 scale of the jetting tool model and carried out the ground tests to verify the overall trenching performance.

In the case of cohesive soil such as clay, it still can carry out a series of laboratory experiments to investigate and evaluate the jetting nozzle's trenching performance $[8,9]$. However, the targeted seafloor soil type of our ROV trencher is a very cohesive one with shear strength less than $40 \mathrm{kPa}$. Thus, we did not carry out the laboratory experiments with clay. Instead, in the case of clay soil, we estimated the trenching performance using empirical formulas such as the jet kerfing model $[10,11]$. The calculated trenching depth estimation is about $1.84 \sim 3.49 \mathrm{~m} \mathrm{[4]}$.

After five years of R\&D works, in October 2018, the finalized ROV trencher named URI-T was put into a $500 \mathrm{~m}$ depth-rated sea trial in the East Sea of Korea to evaluate its final performances [12]. In the trial, through a series of evaluation tests on the $500 \mathrm{~m}$ depth seafloor, it was demonstrated that the maximum trenching depth is $3 \mathrm{~m}$, maximum trenching speed is $2.24 \mathrm{~km} / \mathrm{h}$, and maximum forward speed is $3.12 \mathrm{knots}$ [12]. In addition, moreover, in December 2019, the trencher was thrown into a construction site to bury subsea water pipelines near Yogij Island in South Korea, and successfully carried out the mission with $0.8 \mathrm{~m}$ of average burial depth.

The remainder of this paper is organized as follows: Section 2 describes the water jet tool design methods including CFD simulations, laboratory experiments with one nozzle, and a field test with 1:6 scale jetting tool. In Section 3, two field tests, one being the East Sea trial and the other one being the subsea water pipeline burial operation in Yogji island in South Korea, are presented. In addition, finally a brief conclusion is made in Section 4. 


\section{Design Methods}

The main function of the water jet tool is to properly distribute the water pump's pumping power in order to maximize the trenching performance. In practice, according to the given maximum trench depth requirement, the jetting arm's length can be predetermined so that, when the jetting arm is fully deployed, its end point can approach the maximum depth. Thus, from a design point of view, how to configure the nozzles is the top priority to consider in the tool design. Usually, these nozzles can be classified into two types: one is cutting nozzles which are used to cut the soil and dig a trench, and the other one is backwash nozzles to blow the sediment out of the trench. Nozzle configuration includes how to determine the nozzles arrangement, nozzle gauge, jetting angle, etc., all of which directly affect the trenching performance.

The overall design procedure consists of four successive steps. In Step 1, CFD simulations are carried out to investigate some of the basic concepts such as the effectiveness of nozzle types, Froude similarity, etc. In addition, a series of laboratory tests with one nozzle are performed in Step 2 to investigate and evaluate the relationships between jetting angle, trench depth, trench speed, and jetting power. Then, in order to evaluate the exact trenching performance, a 1:6 scaled jetting tool is manufactured and used in a field test in Step 3. Finally, in Step 4, the prototype water jet tool finishes its design procedure, and manufactures and integrates with the ROV trencher platform.

\subsection{CFD Simulation Studies}

In the first stage of development, T800 ROV trencher, which is owned by KT Submarine [13], was taken as the role model. T800 has the similar trench specifications as in Table 1, and it is equipped with two types of water jetting arms, one is the forward nozzle type and the other one is the back pipe type. Using the mechanical information of these two types of jetting arms combined with the water pump specifications, we carried out the CFD simulations [14] and analyzed the jetting power transmission characteristics. In the case of jetting arm type, see Figure 1a, the average of $40 \mathrm{kPa}$ pressure transmission distance from each nozzle is $0.41 \mathrm{~m}$, which is considered to be sufficient to satisfy the trench depth requirement in Table 1. The average transmission distance, in the case of a back pipe type, see Figure $1 \mathrm{~b}$, is more than $1 \mathrm{~m}$. However, the subsea cable burial field experts in the KT Submarine said that, since there isn't any forward jetting force, the back pipe type is only working well in the case of sand soil. Under these considerations, we proposed a mixed type which takes the both advantages of two types, the details of which will be further discussed in the later section.

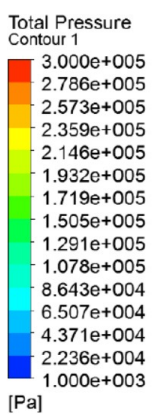

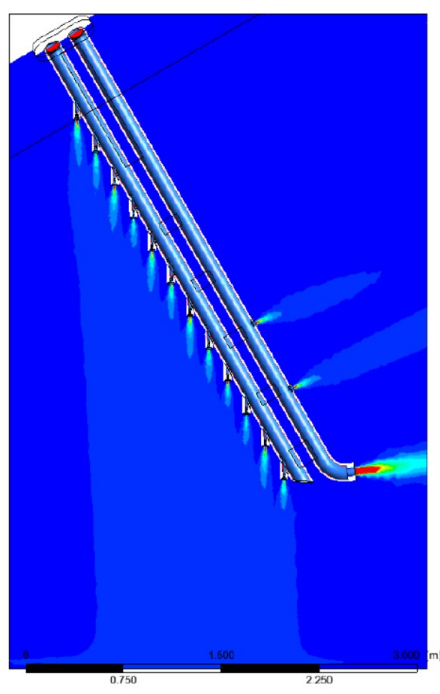

(a) Forward nozzle type.

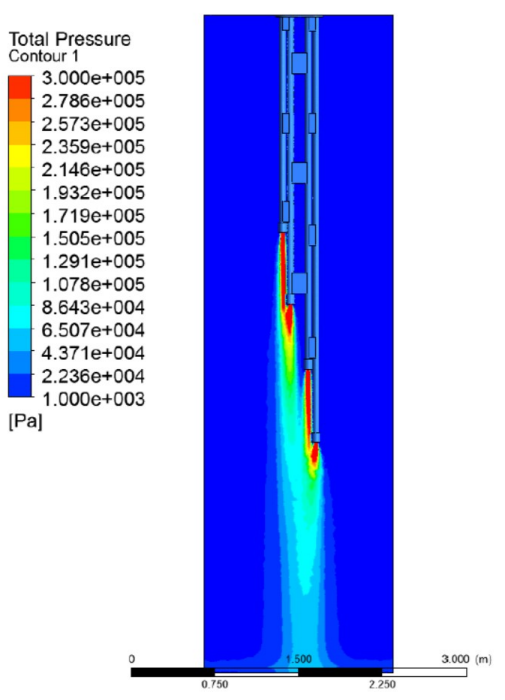

(b) Back pipe type.

Figure 1. CFD simulation test with two types of jetting tools. 
On the other hand, we prepared a laboratory test, which will be presented in the next subsection, with $1 \mathrm{~mm}$ gauge of nozzle. The main purpose of this test is to analyze and estimate the prototype jetting tool's performance using Froude similarity [15-17]. To do so, it is worth carrying out CFD simulations [18] to analyze the pressure distributions outside of the nozzle outlet, and investigate if the CFD results satisfy the Froude similarity. In the simulation, one nozzle is set as a $1 \mathrm{~mm}$ gauge with a $0.0396 \mathrm{~m}^{3} / \mathrm{h}$ flow rate, and the prototype nozzle is taken as a $18 \mathrm{~mm}$ gauge with $54.4 \mathrm{~m}^{3} / \mathrm{h}$ of the flow rate. These two flow rates satisfy the Froude similarity of (2), which is presented in the next subsection. Simulation results are shown in Figure 2 and Table 2.

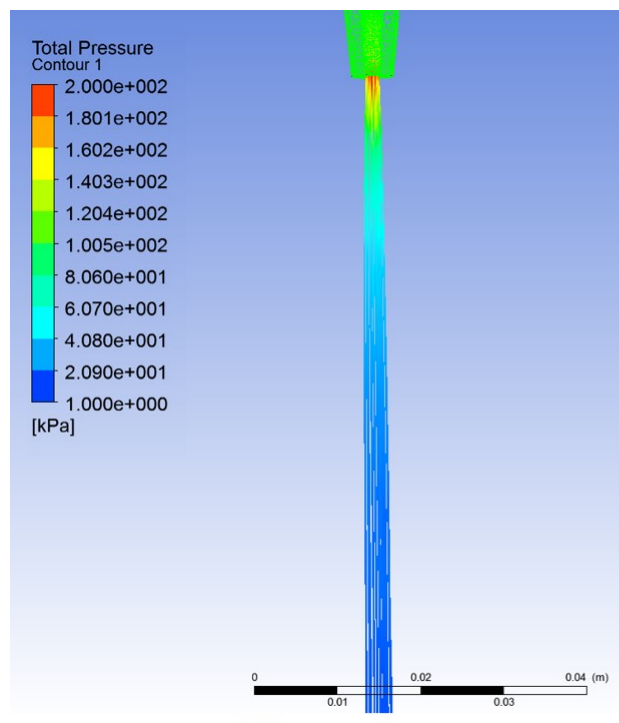

(a) $1 \mathrm{~mm}$ nozzle.

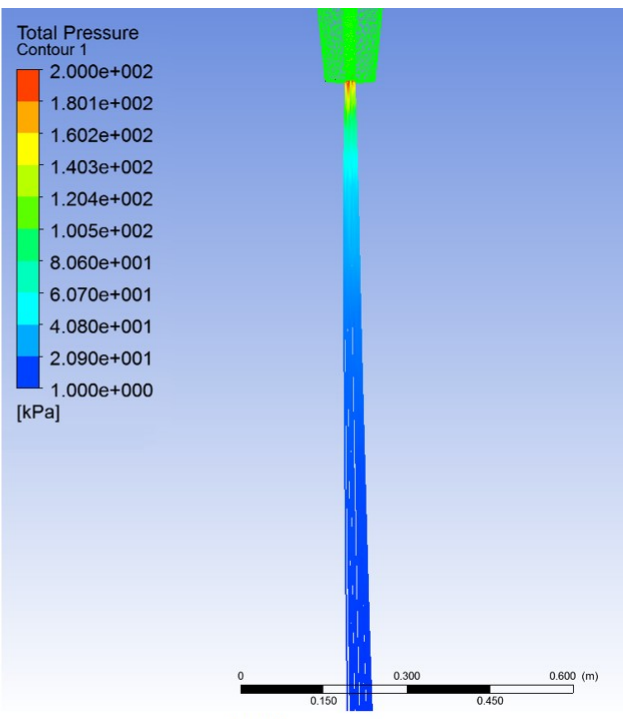

(b) $18 \mathrm{~mm}$ nozzle.

Figure 2. CFD simulation test with two different nozzles.

Table 2. CFD simulation results with $1 \mathrm{~mm}$ and $18 \mathrm{~mm}$ nozzles.

\begin{tabular}{ccccc}
\hline & \multicolumn{2}{c}{ 1 mm Nozzle } & \multicolumn{2}{c}{ 18 mm Nozzle } \\
\hline Flow rate $\left(\mathrm{m}^{3} / \mathrm{h}\right)$ & \multicolumn{2}{c}{0.0396} & \multicolumn{2}{c}{54.4} \\
\hline Range $(\mathrm{cm})$ & Speed $(\mathrm{m} / \mathrm{s})$ & Pressure $(\mathrm{kPa})$ & Speed $(\mathrm{m} / \mathrm{s})$ & Pressure $(\mathrm{kPa})$ \\
\hline Near outlet & 14.6 & 99.2 & 60.5 & 1837 \\
\hline $1(18)$ & 4.4 & 12.1 & 11.4 & 60 \\
\hline $2(36)$ & 0.85 & 3.7 & 7.3 & 26 \\
\hline
\end{tabular}

The laboratory test nozzle gauge is $1 \mathrm{~mm}$ and the prototype nozzle is $18 \mathrm{~mm}$, so the scale factor (SF) is 18. From Table 2, we can see that the flow speeds near the outlet in two cases are each $14.6 \mathrm{~m} / \mathrm{s}$ and $60.5 \mathrm{~m} / \mathrm{s}$, which approximately satisfy $60.5 / 14.6=4.14 \approx$ $\sqrt{S F}=4.24$. In the case of near outlet pressure, we have $1837 / 99.2=18.5 \approx S F$. Therefore, in the case of near nozzle outlet, the flow speed and pressure are approximately satisfying the Froude similarity of (1) and (3). However, from the table, we can see that even a little bit far away from the outlet, these similarities are no more satisfying.

\subsection{Laboratory Experiment}

In the jetting arm design, how to determine the nozzles' jetting angle, especially the cutting nozzles' jetting angle is one of the most important consideration. This nozzles jetting angle is closely related to the trenching performance such as trench depth, trench speed (also called traverse rate). In order to investigate the relationships between jetting 
angle, trench depth, trench speed, and jetting power, a series of experiments have been carried out in the laboratory environment.

\subsubsection{Experiment Setup}

The laboratory experiment setup is as shown in Figure 3 [4]. The glass wall tank dimension is $1.0(\mathrm{~L}) \times 0.5(\mathrm{H}) \times 0.15(\mathrm{~W}) \mathrm{m}$. Sandy soil, whose median diameter is about 0.1 $\mathrm{mm}$, is laid on the tank floor with about $0.2 \mathrm{~m}$ of thickness. The $1 \mathrm{~mm}$ gauge of nozzle is installed on the wheeled carriage whose moving speed $(\leq 0.13 \mathrm{~m} / \mathrm{s}$ with $0.001 \mathrm{~m} / \mathrm{s}$ of resolution) can be adjusted using a velocity tuner. The nozzle's jetting angle can also be adjusted using a jetting angle adjustment apparatus shown in Figure 3. The water pump flow rate is $3 \mathrm{~m}^{3} / \mathrm{h} @ 2$ bar and its maximum RPM is 1765 . There is a pressure gauge and flowmeter installed near the pump outlet.

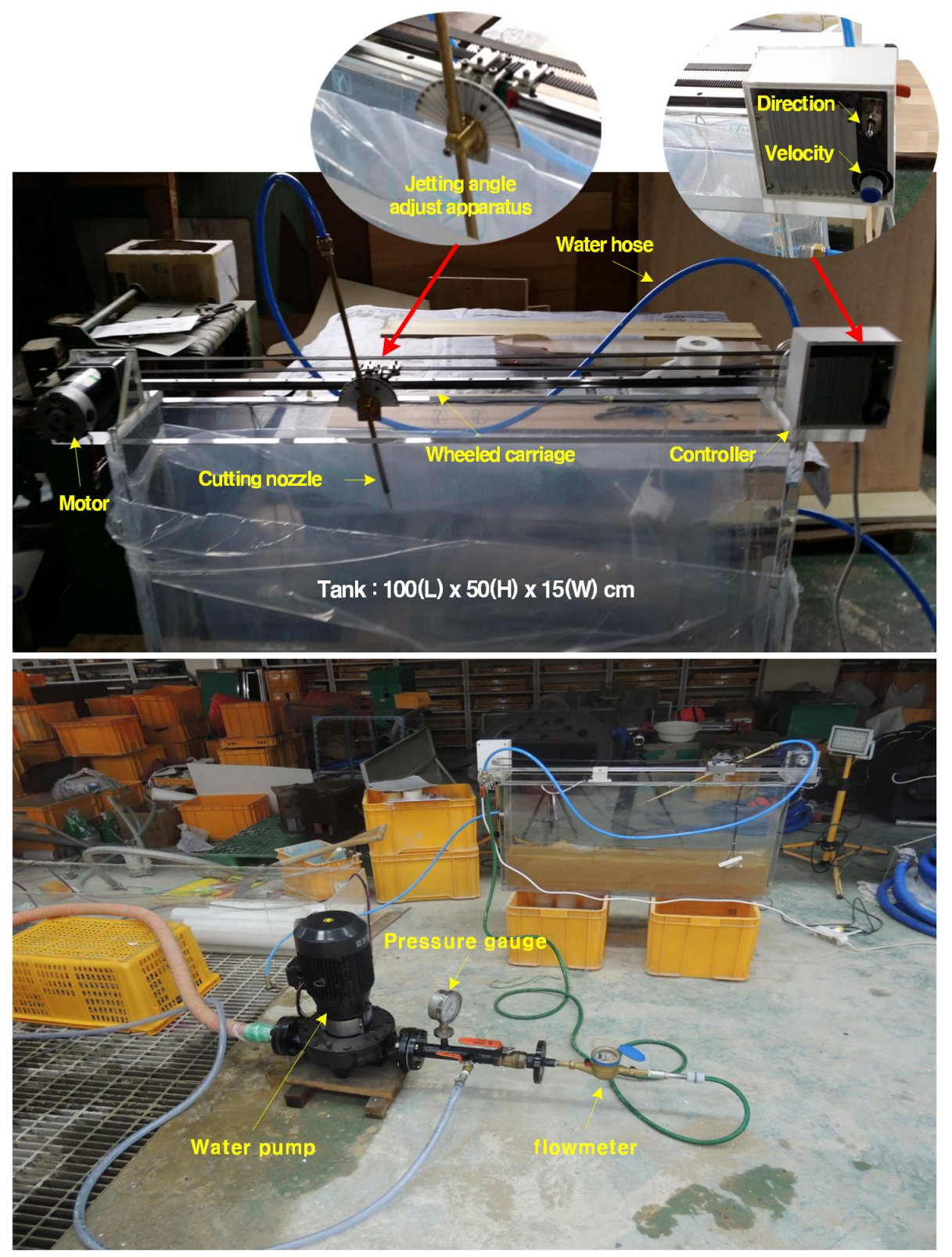

Figure 3. Laboratory experimental apparatus setup.

\subsubsection{Jetting Angle Test}

First, we want to investigate the relationship between the jetting angle and trench depth. To do so, the jetting angle is tuned from $40^{\circ}$ to $95^{\circ}$ with each step of $50^{\circ}$ increasing. 
In each jetting angle, we also adjust the carriage velocity (nozzle trench speed) as $v_{t r}=0.3$, $0.6,1.2 \mathrm{~cm} / \mathrm{s}$. Figure 4 shows some of the test results, and the relationship between the jetting angle and trench depth is shown in Figure 5, from which it is easy to see that the trench becomes deeper as the jetting angle increases, and shallower with an increasing nozzle traverse rate. However, from Figures 6 and 7, we can see that increasing the jetting angle will cause the trench entrance to become narrower. This indicates that there is more swift sediment deposition if we increase the jetting angle. In practice, this might require more backwash power to blow out the floating soil materials, and this backwash power increasing will naturally cause the decreasing of cutting nozzles' jetting power and eventually cause the degradation of trenching performance. Therefore, for given trenching performance, how to design the jetting angle should be carefully considered in practice. For the URI-T jet tool, which consists of three back pipes with forward nozzles mounted on them, the maximum deploying angle of back pipes is $60^{\circ}$ and the forward cutting nozzles' maximum jetting angle is $90^{\circ}$.

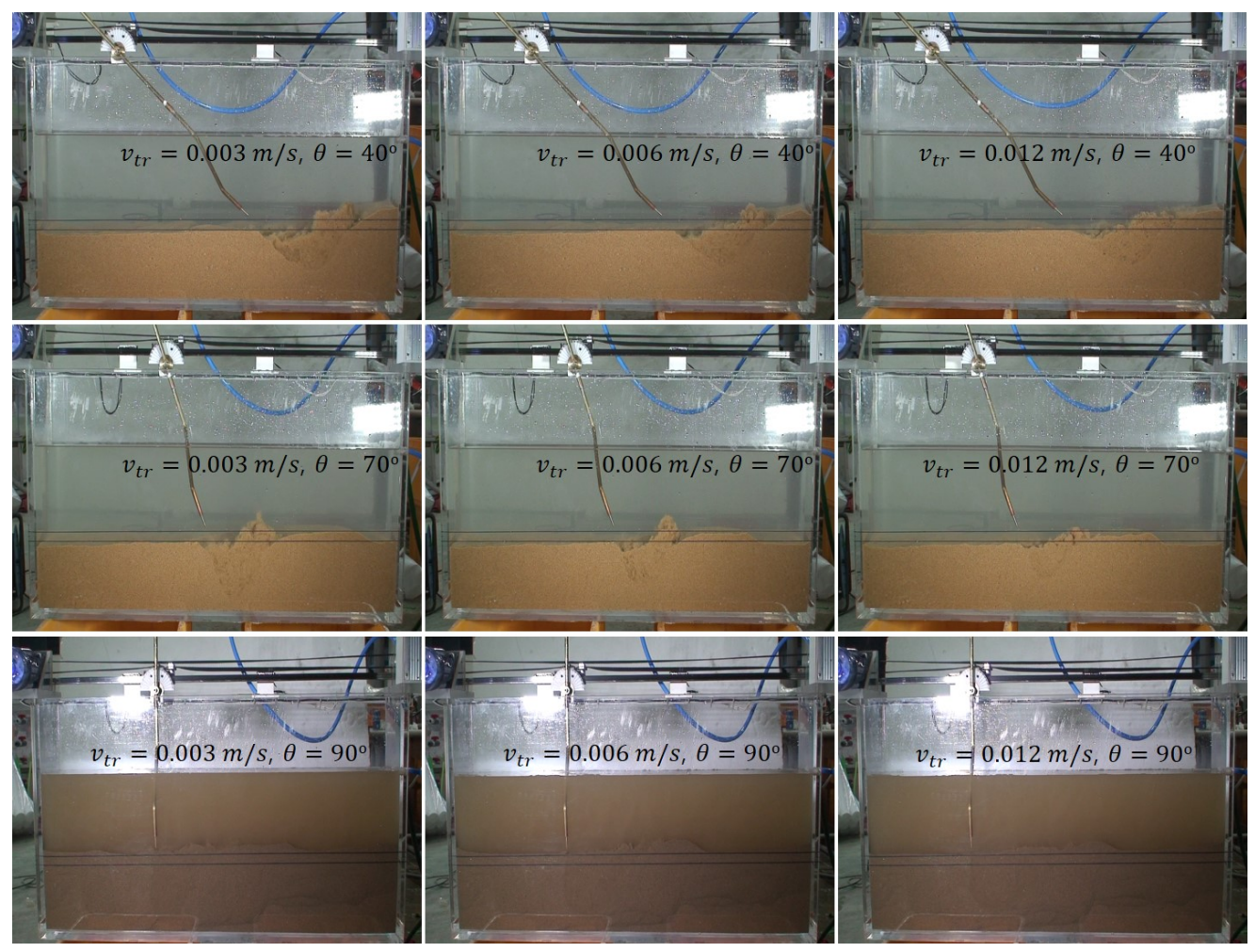

Figure 4. Some of the jetting angle experiment results. 


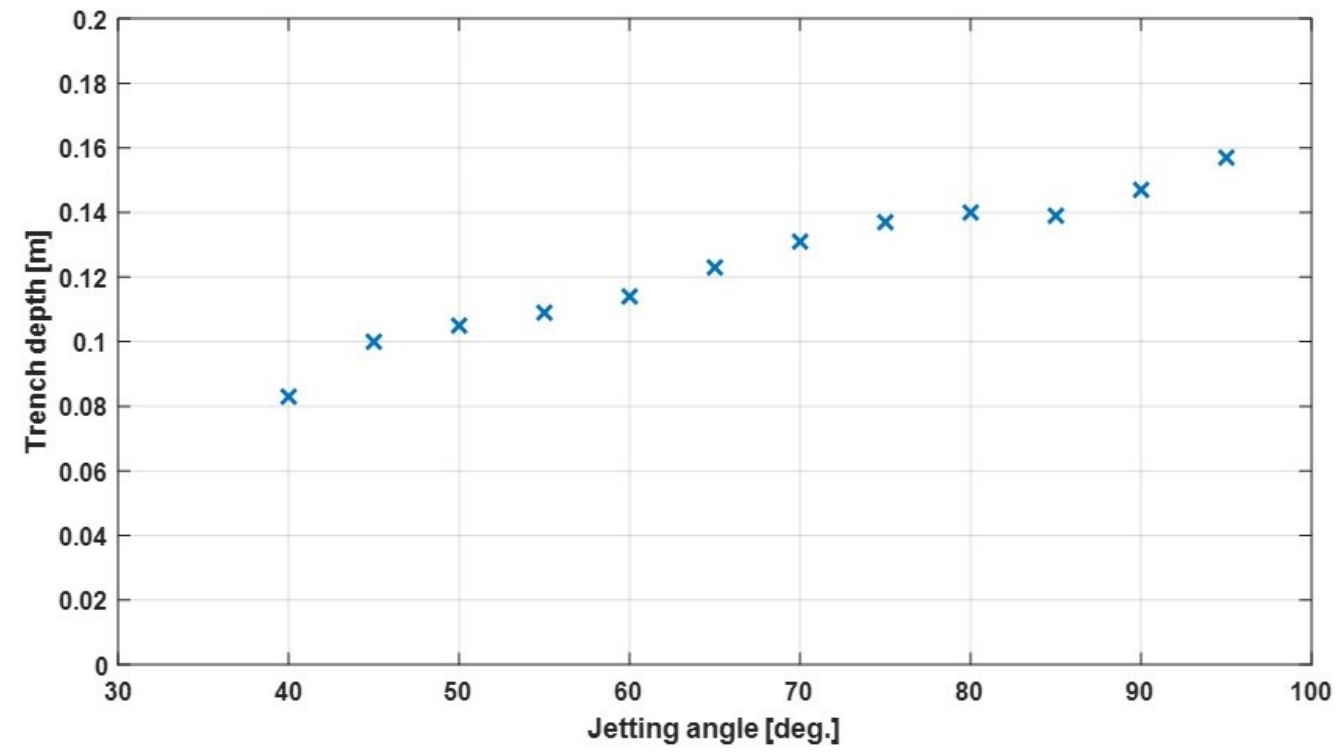

Figure 5. Jetting angle vs. trench depth.
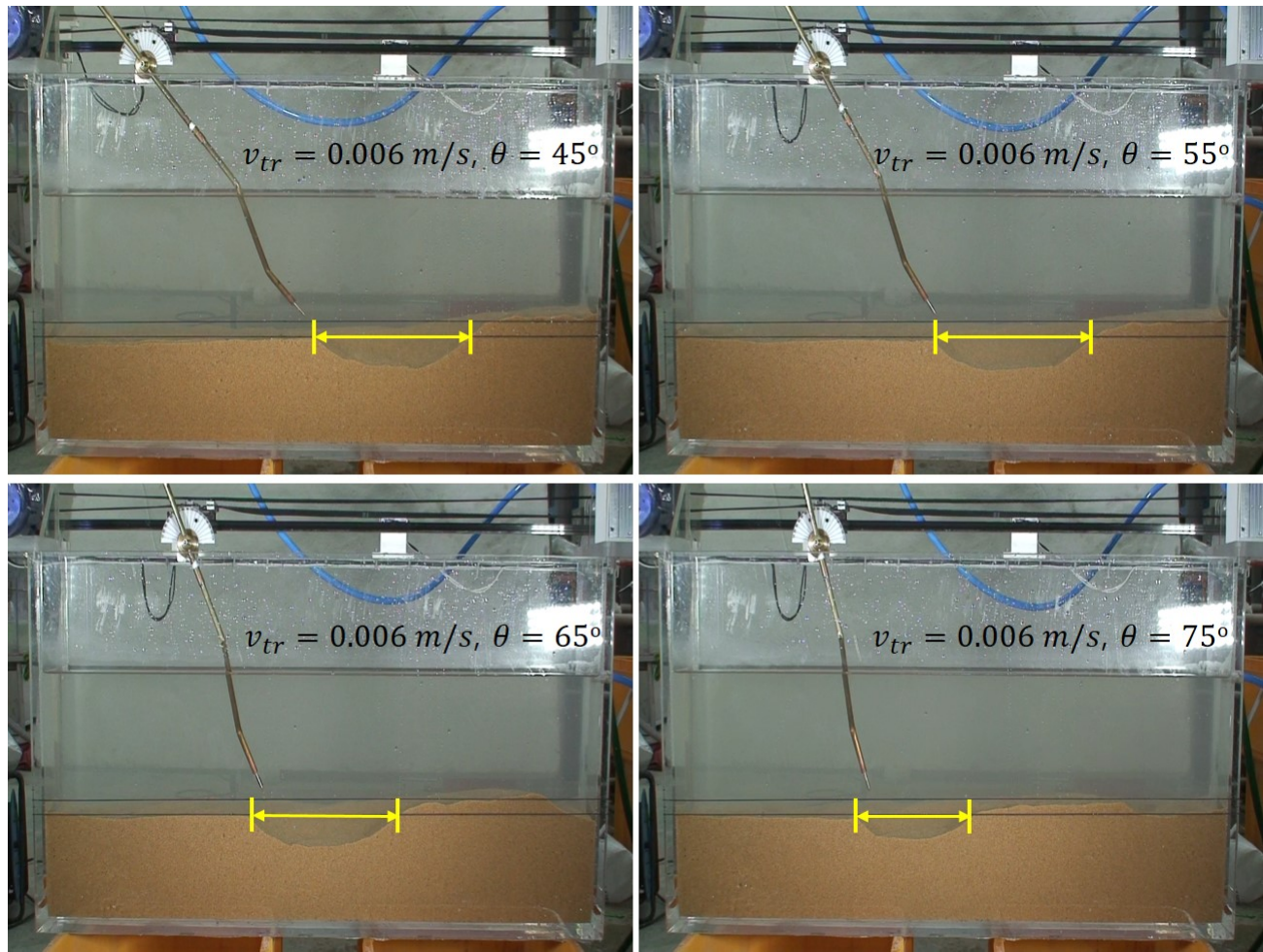

Figure 6. Trench entrance becomes narrower with increasing jetting angles. 


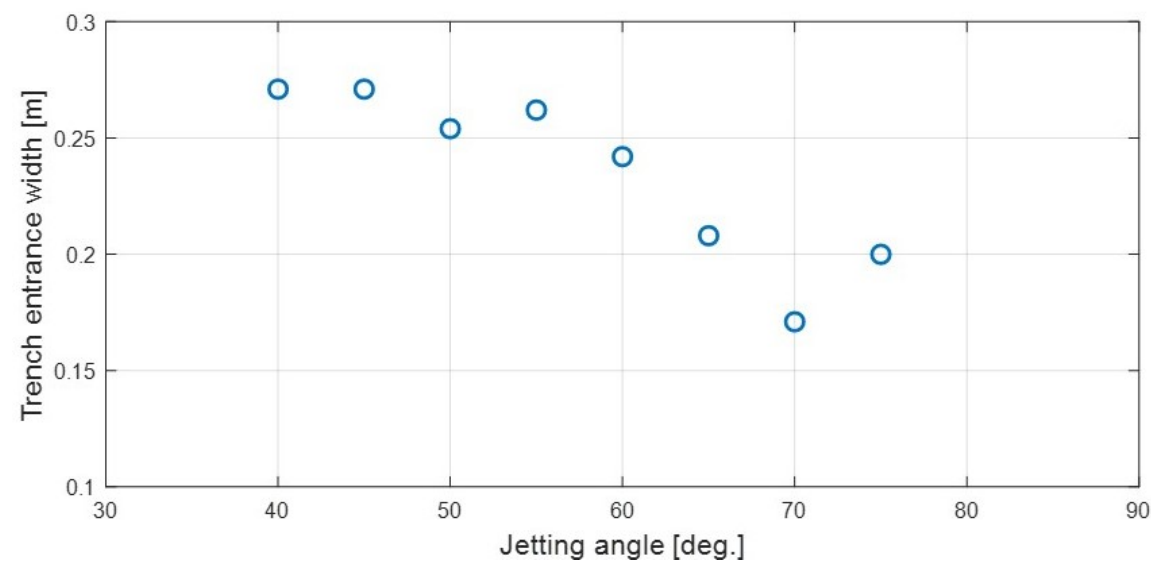

Figure 7. Jetting angle vs. trench entrance width.

\subsubsection{Jetting Power Experiment}

This time, we want to investigate the relationship between trench depth, trench speed, and jetting power, from which the trenching performance of prototype trencher can be roughly assessed. In the test, the jetting angle is fixed as $60^{\circ}$, and the pump RPM is tuned with seven different cases, and we investigate the corresponding trench depths with different traverse rates. Pump RPM is tuned as 200, 350, 500, 700, 1050, 1400, and $1760 \mathrm{r} / \mathrm{min}$, and corresponding flow rates and pressures are each measured by flowmeter and pressure gauge installed near the pump outlet, see Figure 3. Jetting powers are calculated by multiplying the above flow rates and pressures, see Table 3 .

Table 3. Pump RPM and corresponding flow rate, pressure, and jetting power.

\begin{tabular}{lccccccc}
\hline Item & Case-1 & Case-2 & Case-3 & Case-4 & Case-5 & Case-6 & Case-7 \\
\hline RPM $(\mathrm{r} / \mathrm{min})$ & 200 & 350 & 500 & 700 & 1050 & 1400 & 1760 \\
\hline Flow rate $\left(\mathrm{m}^{3} / \mathrm{h}\right)$ & 0.0097 & 0.0115 & 0.014 & 0.018 & 0.0252 & 0.0324 & 0.0396 \\
\hline Pressure $($ bar $)$ & 0.01 & 0.02 & 0.18 & 0.2 & 0.5 & 0.8 & 1.15 \\
\hline Jetting power $(\mathrm{W})$ & 0.0008 & 0.0018 & 0.0195 & 0.0278 & 0.0972 & 0.2 & 0.3514 \\
\hline
\end{tabular}

For given pump RPM, the nozzle traverse rates are tuned as $v_{t r}=0.5,1.0,1.5,2.5,4.0$, 6.0 , and $8.0 \mathrm{~cm} / \mathrm{s}$, and we investigate the corresponding trench depths. Test results are shown in Table 4.

Table 4. Trench depths with different nozzle traverse rate and jetting power.

\begin{tabular}{cccccccc}
\hline \multirow{2}{*}{$v_{t r}(\mathbf{c m} / \mathbf{s})$} & \multicolumn{7}{c}{ Trench Depth $(\mathbf{m})$} \\
\cline { 2 - 8 } & Case-1 & Case-2 & Case-3 & Case-4 & Case-5 & Case-6 & Case-7 \\
\hline 0.5 & 1.8 & 2.0 & 3.0 & 3.4 & 5.0 & 5.6 & 7.0 \\
1.0 & 1.6 & 1.8 & 3.0 & 3.4 & 4.8 & 5.6 & 6.8 \\
1.5 & 1.4 & 1.7 & 2.6 & 3.2 & 4.6 & 5.4 & 6.6 \\
2.5 & 0.8 & 1.2 & 1.6 & 2.8 & 4.2 & 5.4 & 6.4 \\
4.0 & 0.8 & 1.0 & 1.2 & 2.0 & 3.4 & 4.6 & 5.6 \\
6.0 & 0.6 & 0.8 & 1.2 & 1.6 & 2.6 & 3.6 & 4.8 \\
8.0 & 0.4 & 0.6 & 0.8 & 1.0 & 2.2 & 3.4 & 4.0 \\
\hline
\end{tabular}




\subsubsection{Froude Similarity and Estimated Trenching Performance}

Considering the water jet tool is an open-channel hydraulic system where friction effects can be negligible, in this laboratory modeling test, we apply the Froude similarity to predict the prototype jetting tool's non-geometrical variables, such as velocities, discharge, power, etc. $[6,7,16,17,19]$. In the case of high pressure water jetting, the fluid flow is mainly caused by the water pump power instead of the gravity force. Therefore, we can avoid the possible scale effects in the laboratory test governed by Froude similarity [6,19]. In addition, a $1 \mathrm{~mm}$ gauge of nozzle is used in the laboratory modeling test, and supposing that the prototype cutting nozzle gauge is $18 \mathrm{~mm}$, then the scale factor (SF) is 18 . According to this parameter, we can estimate all the non-geometrical variables such as prototype trench speed, flow rate, pressure, and jetting power as well as the trench depth using Froude similarity $[16,17]$ as follows:

$$
\begin{aligned}
\frac{v_{t r, p}}{v_{t r, m}} & =\sqrt{S F}, \\
\frac{Q_{p}}{Q_{m}} & =(S F)^{\frac{5}{2}}, \\
\frac{p_{p}}{p_{m}} & =S F, \\
\frac{P_{p}}{P_{m}} & =(S F)^{\frac{7}{2}},
\end{aligned}
$$

where $v_{t r}$ is trench speed; $Q, p$, and $P$ each denote flow rate, pressure, and jetting power; subscript $p$ and $m$ each indicate prototype and model.

By applying the Froude similarity to the laboratory experiment results shown in Table 4, we can get the estimation of the relationship between the prototype jetting power, trench speed, and trench depth as shown in Figure 8.

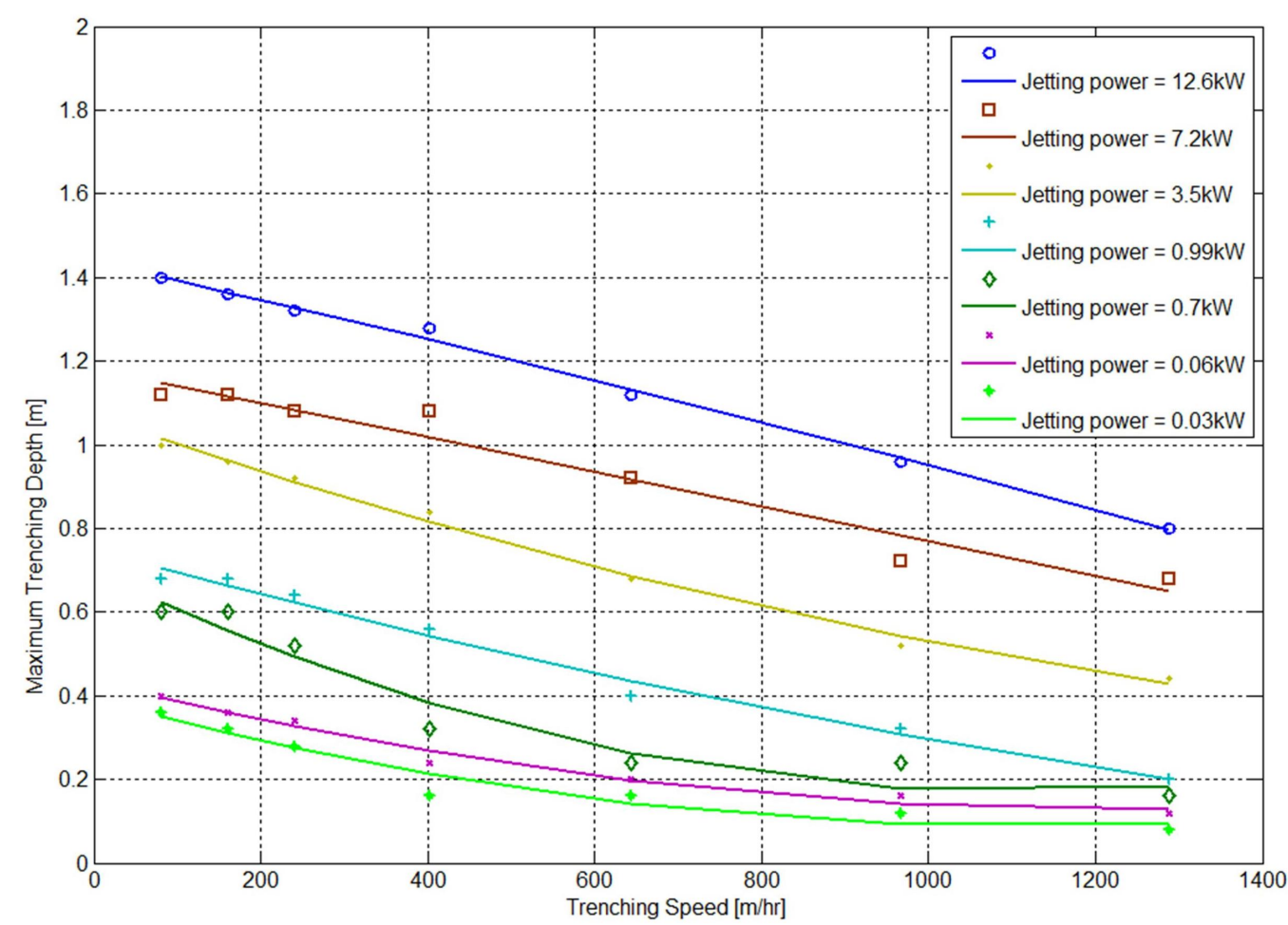

Figure 8. Influence of jetting power and trench speed on the maximum trench depth.

Now, consider a prototype jetting arm whose configuration is as shown in Figure 9. Suppose that the water pump power is $250 \mathrm{shp}$ (about $184 \mathrm{~kW}$ ). Indeed, the water pump power of T800 trencher owned by KT Submarine [13] is $250 \mathrm{shp}$. The jetting arm only 
consists of 18 cutting nozzles and one backwash nozzle, and the ratio of cutting power to backwash power is set to 3:1. In this case, each cutting nozzle jetting power is about $7.8 \mathrm{~kW}$. With this jetting power, from Figure 8, we can see that each nozzle trench depth is more than $0.6 \mathrm{~m}$ with about $1.3 \mathrm{~km} / \mathrm{h}$ of trench speed. In addition, if we extend the graph related to $7.2 \mathrm{~kW}$ jetting power in Figure 8, then we can get the trend as shown in Figure 10, from which we can see that, with $2 \mathrm{~km} / \mathrm{h}$ of trench speed, each nozzle's trench depth still exceeds $0.3 \mathrm{~m}$. All of these indicate that the jetting arm, whose configuration is as shown in Figure 9 , can satisfy the $3 \mathrm{~m}$ of trench depth.

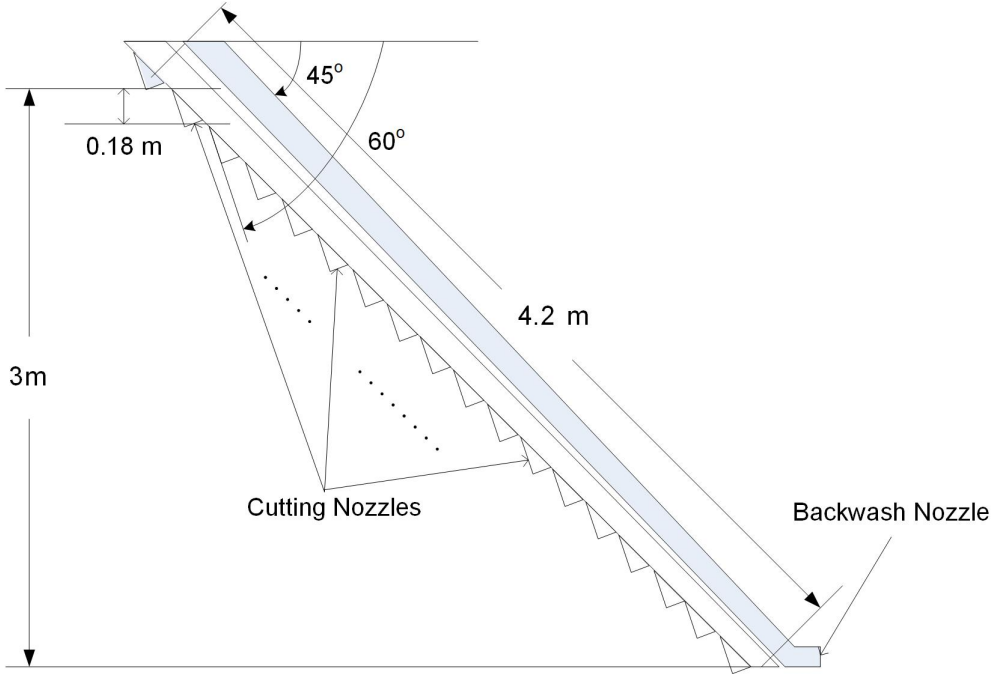

Figure 9. Example of a jetting arm configuration.

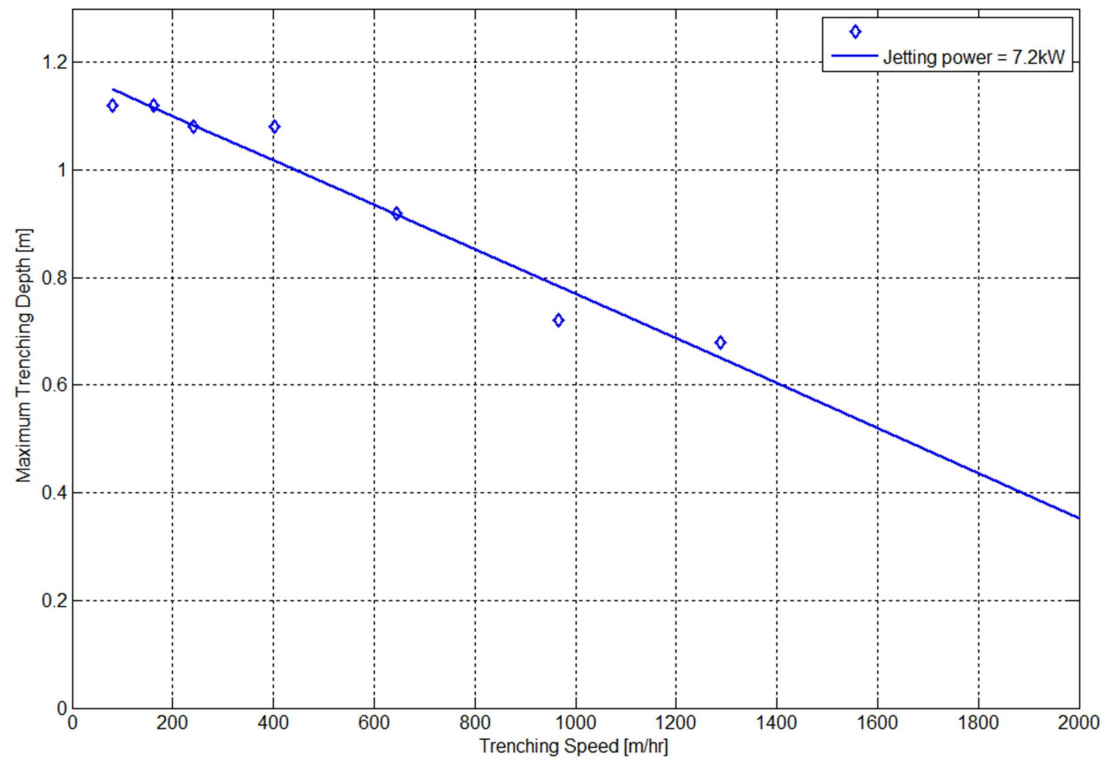

Figure 10. Extended trend of jetting power and trench speed on the maximum trench depth.

\subsection{Field Test Using 1:6 Scale Jetting Tool}

In addition to the laboratory experiments, we also carried out a series of ground field tests using a 1:6 scale prototype to evaluate the trenching performance.

\subsubsection{Test Setup}

First, an excavator is applied to excavate a trench with $30 \mathrm{~m}$ long, $1 \mathrm{~m}$ width, and about $0.7 \sim 0.8 \mathrm{~m}$ depth on the ground. Then, 20 tons of sand $(\phi=0.2 \mathrm{~mm})$ and two tons of 
clay sand $(\phi=0.01 \sim 0.05 \mathrm{~mm}$ ) are mixed and filled in the trench. The test apparatus setup is as shown in Figure 11.

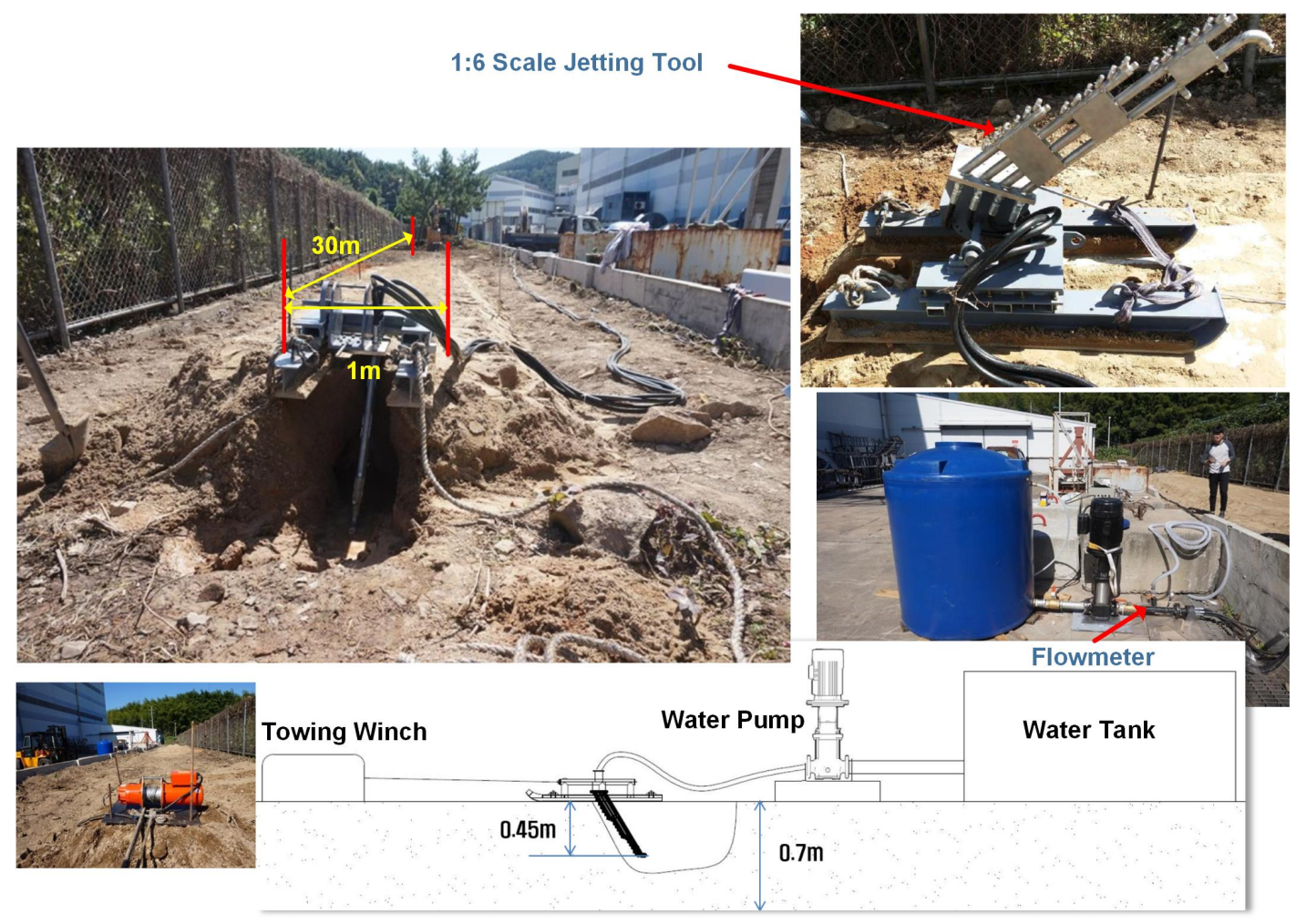

Figure 11. Ground field test setup.

The flow rate of prototype water pump is pre-defined as $Q_{p}=986 \mathrm{~m}^{3} / \mathrm{h}$. Thus, in the field test, the flow rate is controlled to keep the following value:

$$
Q_{m}=Q_{p} /(S F)^{\frac{5}{2}}=11.2 m^{3} / h .
$$

In addition, it is worth mentioning that, when the winch is towing the jetting sled, there are always two researchers following the sled and pushing down the rear part of the sled to prevent its lifting by jetting reaction force. In practice, this kind of push down the platform is usually carried out by increasing the rear vertical thrust.

\subsubsection{Case Studies}

From Figure 11, it can be seen that the 1:6 scale jetting tool consists of three different types of nozzles: 18 forward cutting nozzles $(\phi=3 \mathrm{~mm})$, three back pipe nozzles $(\phi=$ $6 \mathrm{~mm})$, and three backwash nozzles $(2 \times 3.5 \mathrm{~mm}, 1 \times 8.4 \mathrm{~mm})$. As mentioned before, this is a sort of mixed configuration of two different types of jetting tools in [13].

Field tests are performed through seven different cases as seen in Table 5, where the jetting tool deployed angle is set to 60 degrees. The maximum trench speed $22.68 \mathrm{~cm} / \mathrm{s}$ is set through $v_{t r}^{m}=v_{t r}^{p} / \sqrt{S F}=(2 / \sqrt{6}) \mathrm{km} / \mathrm{h}=22.68 \mathrm{~cm} / \mathrm{s}$. 
Table 5. Seven different cases in the ground field test.

\begin{tabular}{lll}
\hline Cases & Trench Speed & Applied Nozzles \\
\hline Case-1 & $5.67 \mathrm{~cm} / \mathrm{s}$ & Forward cutting(18)+Back pipe(3)+Backwash(3) \\
Case- 2 & $11.34 \mathrm{~cm} / \mathrm{s}$ & Forward cutting(18)+Back pipe(3)+Backwash(3) \\
Case-3 & $17.01 \mathrm{~cm} / \mathrm{s}$ & Forward cutting(18)+Back pipe(3)+Backwash(3) \\
Case- 4 & $22.68 \mathrm{~cm} / \mathrm{s}$ & Forward cutting(18)+Back pipe(3)+Backwash(3) \\
Case-5 & $22.68 \mathrm{~cm} / \mathrm{s}$ & Forward cutting(18)+Back pipe(3) \\
Case-6 & $22.68 \mathrm{~cm} / \mathrm{s}$ & Forward cutting(18)+Backwash(3) \\
Case-7 & $22.68 \mathrm{~cm} / \mathrm{s}$ & Back pipe(3) \\
\hline
\end{tabular}

\subsubsection{Test Results}

Experiment results are shown in Table 6.

Table 6. Ground field test results.

\begin{tabular}{llll}
\hline Cases & Trench Speed & Target Trench Depth & Trenched Depth \\
\hline Case-1 & $5.67 \mathrm{~cm} / \mathrm{s}$ & $0.5 \mathrm{~m}$ & $0.7 \mathrm{~m}$ \\
Case-2 & $11.34 \mathrm{~cm} / \mathrm{s}$ & $0.5 \mathrm{~m}$ & $0.7 \mathrm{~m}$ \\
Case-3 & $17.01 \mathrm{~cm} / \mathrm{s}$ & $0.5 \mathrm{~m}$ & $0.7 \mathrm{~m}$ \\
Case-4 & $22.68 \mathrm{~cm} / \mathrm{s}$ & $0.5 \mathrm{~m}$ & $0.65 \mathrm{~m}$ \\
Case-5 & $22.68 \mathrm{~cm} / \mathrm{s}$ & $0.5 \mathrm{~m}$ & $0.55 \mathrm{~m}$ \\
Case-6 & $22.68 \mathrm{~cm} / \mathrm{s}$ & $0.5 \mathrm{~m}$ & $0.55 \mathrm{~m}$ \\
Case-7 & $22.68 \mathrm{~cm} / \mathrm{s}$ & $0.5 \mathrm{~m}$ & - \\
\hline
\end{tabular}

According to Froude similarity $[16,17]$, since $S F=6$, target trench depth is set to $0.5 \mathrm{~m}$. In Case-1 to Case-4, it is found that the target trench depth and speed are all easy to be satisfied. However, in Cases-5 and 6, the trench depths are only satisfied in the case with slow down the trench speed. In addition, in Case-7, it is investigated that even changing the jetting tool deployment angle, it is still difficult to move the jetting sled forward.

\subsection{Final Design}

Figure 12 shows the final mechanical design of prototype water jetting tool, and the manufactured prototype and its installation on the trencher platform are also depicted. It is easy to see that the jetting arm consists of three different types of nozzles: 18 forward cutting nozzles $(\phi=18 \mathrm{~mm})$, three back pipe nozzles $(\phi=90 \mathrm{~mm}$, which can be blocked by blind caps), and three backwash nozzles $(2 \times 22 \mathrm{~mm}, 1 \times 50 \mathrm{~mm})$.

The length of jetting arm is $4.02 \mathrm{~m}$, so in the case of its full deployment of $60 \mathrm{deg}$, the maximum vertical reaching depth of jetting arm end point from the mounting bracket is about $3.48 \mathrm{~m}$. This includes the $0.45 \mathrm{~m}$ of estimated height of the jetting arm mounting bracket from the trencher skid floor. 

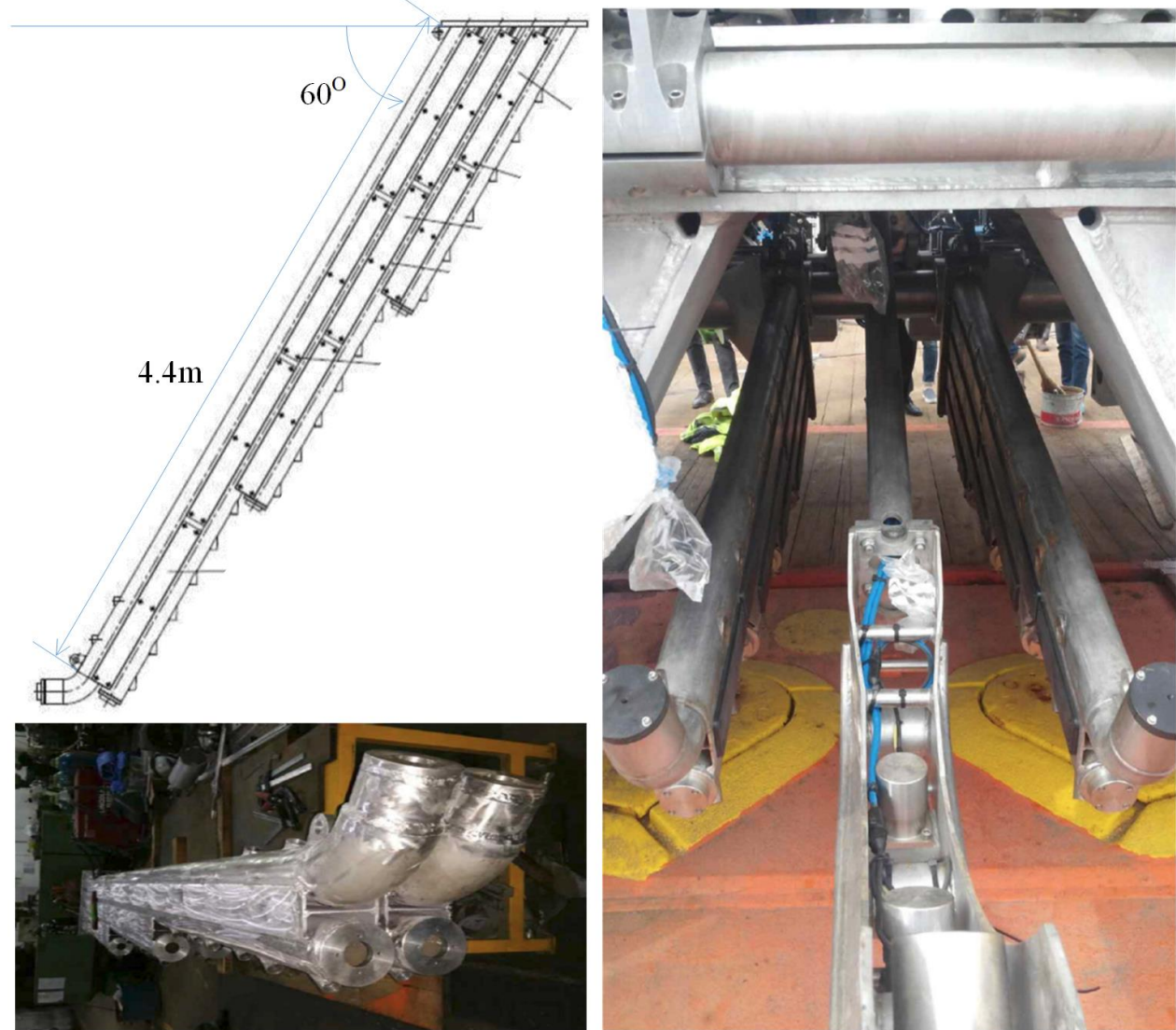

Figure 12. Final prototype design and its installation on the trencher platform.

\section{Performance Evaluations through Field Tests}

\subsection{East Sea Trial}

As mentioned before, after five years of R\&D works, in October 2018, the finalized ROV trencher named URI-T was put into a $500 \mathrm{~m}$ depth sea trial in the East Sea of Korea to verify if it was satisfying the trenching specifications listed in Table 1.

Two surface vessels, Segero-ho and Miraero-ho, both of which are owned by KT Submarine Co., were applied in the trial. Segero-ho was in charge of operating URI-T while Miraero-ho was the operating tone generator to provide tone signals in the cable in order for URI-T to detect the cable on the seafloor using TSS350 (a cable detection system), see Figure 13. 

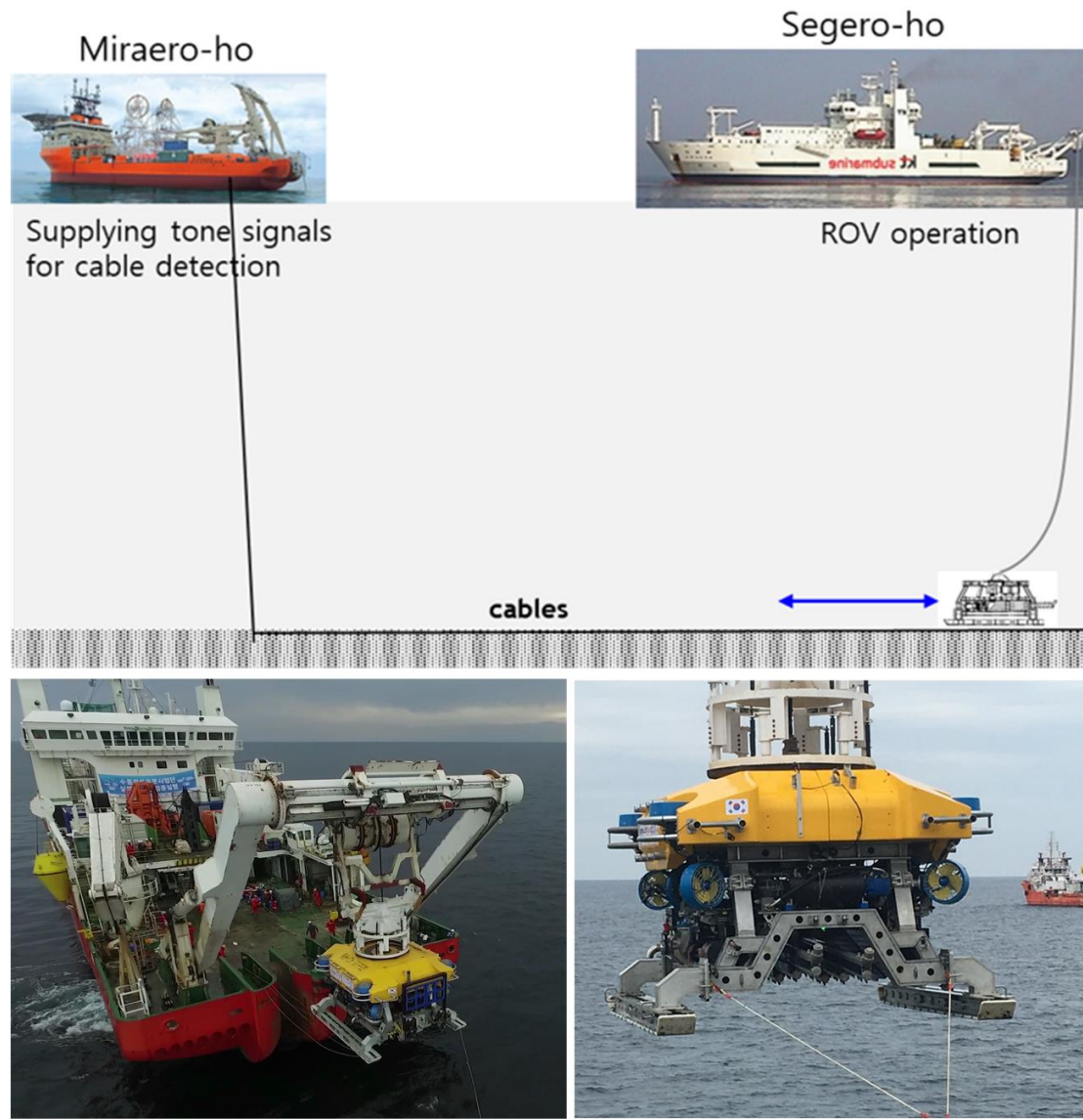

ROV operation

Figure 13. East Sea trial in October 2018.

\subsubsection{Verification of $3 \mathrm{~m}$ Maximum Trench Depth}

On the $509 \mathrm{~m}$ depth seafloor, two water jetting arms were fully deployed using corresponding hydraulic cylinders while keeping certain jetting pressure. Under this condition, the trencher was manually operated to move forward about $7 \mathrm{~m}$, see Figure 14. In addition, this verified the satisfaction of the specification of the $3 \mathrm{~m}$ maximum trench depth.

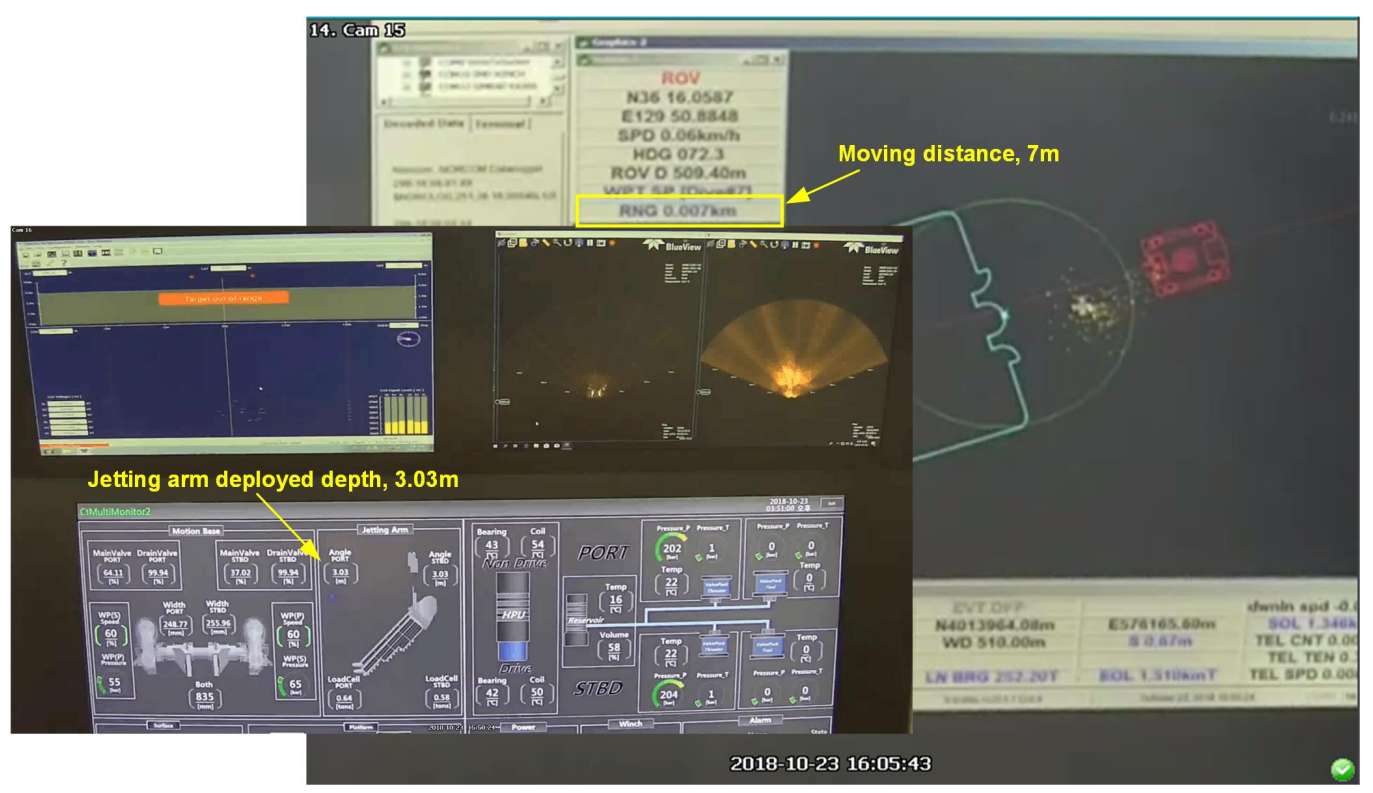

Figure 14. Verification of $3 \mathrm{~m}$ maximum trench depth. 
In addition, we carried out a cable burial test which is very similar to the real practical cases. At first, the two jetting arms were deployed by $1.2 \mathrm{~m}$ depth, and buried the cable about $100 \mathrm{~m}$ long distance. In addition, then, the trencher was turned backwards and continued to bury the cable. However, this time, the jetting arms were deployed by $2.2 \mathrm{~m}$ depth. In addition, the third and also the final turn were carried out by fully deploying the jetting arms (3.03 $\mathrm{m}$ depth). The survey result using TSS350 showed that the average burial depth was about $2.4 \mathrm{~m}$ below the seafloor, see Figure 15 .

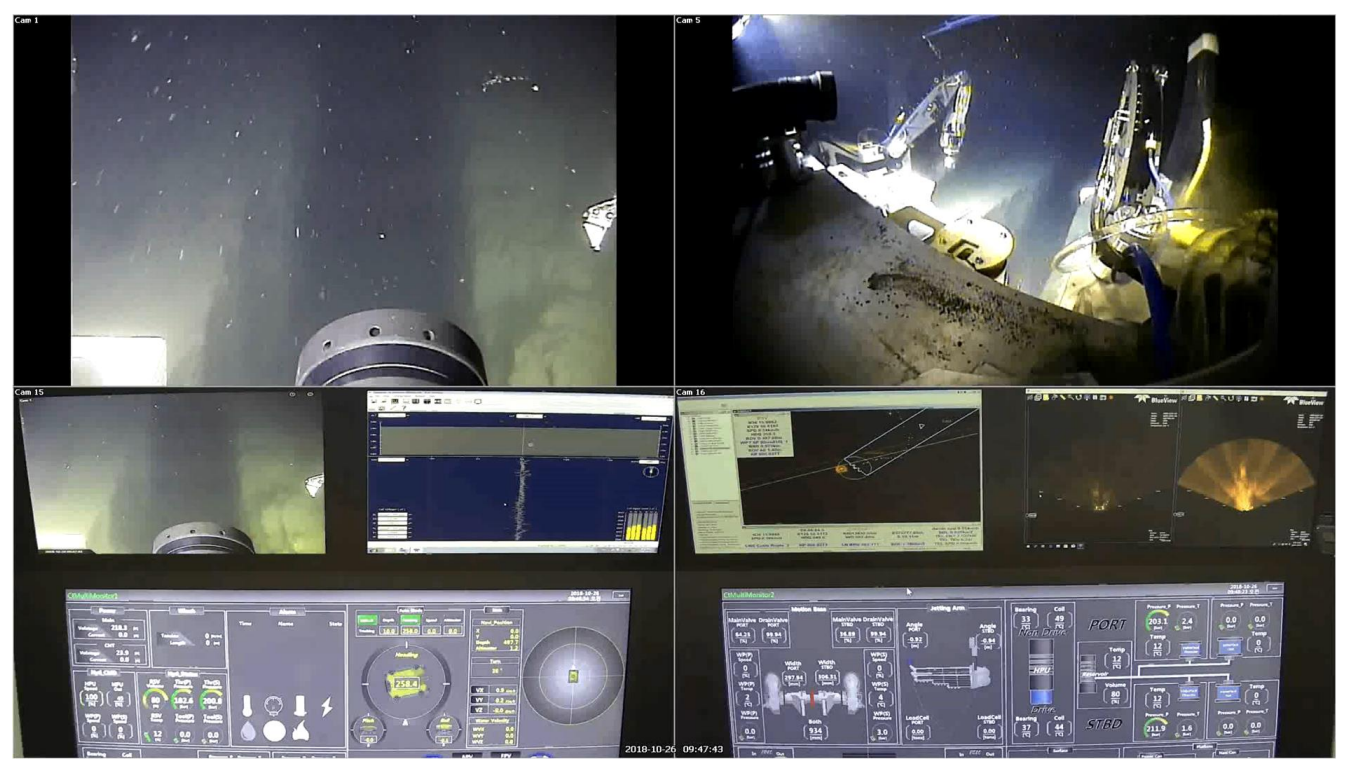

Figure 15. Post survey of cable burial tests.

\subsubsection{Verification of $2 \mathrm{~km} / \mathrm{h}$ Maximum Trench Speed}

In this test, the jetting arms were deployed by $1 \mathrm{~m}$ depth, and the trencher was manually operated to move forward more than $200 \mathrm{~m}$. During this move, there were two acceleration sections. By enlarging the $34.25 \mathrm{~m}$ length of the second section, we can see that the average forward speed is about $2.24 \mathrm{~km} / \mathrm{h}$ (see Figure 16), which can verify the satisfaction of the second specification that is $2 \mathrm{~km} / \mathrm{h}$ of maximum trench speed.
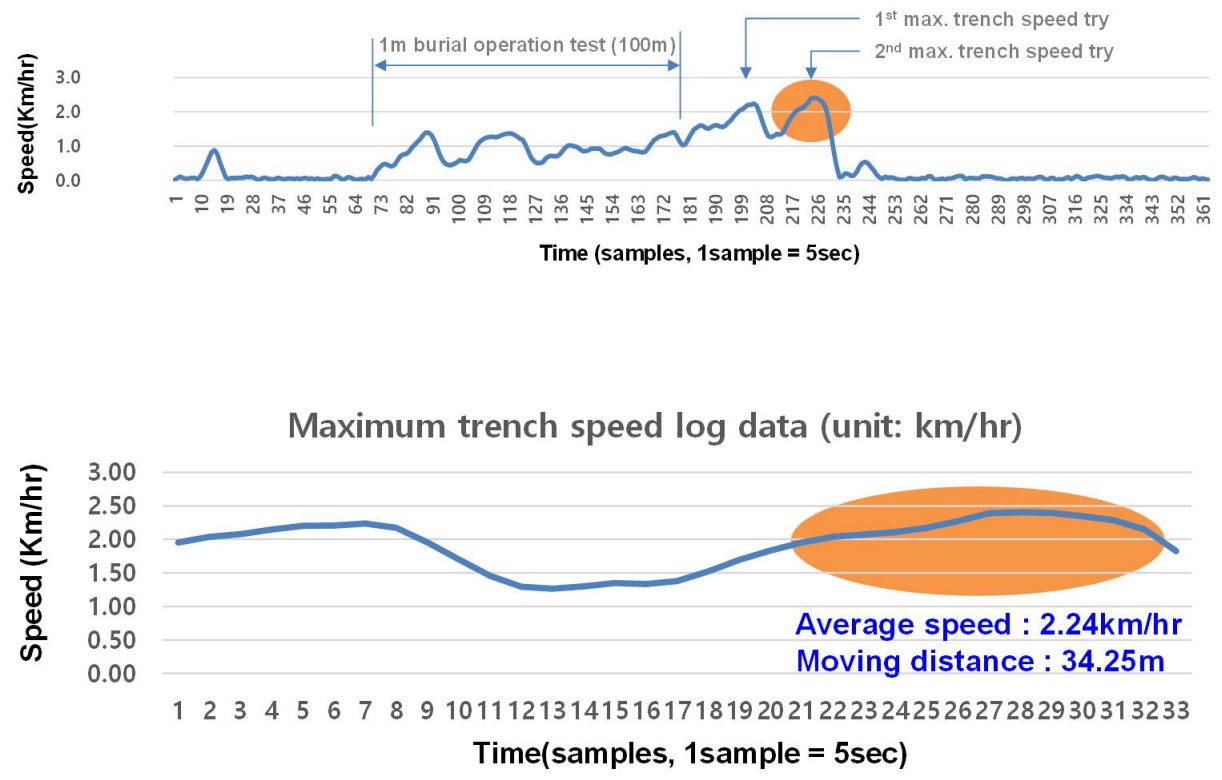

Figure 16. Verification of $2 \mathrm{~km} / \mathrm{h}$ of maximum trench speed. 


\subsection{Subsea Water Pipeline Burial}

In December 2019, URI-T was put into a subsea construction site. This contract was ordered by Tongyeong city, Gyeongsangnam-do, Republic of Korea. The purpose is to bury subsea water pipelines connecting Yogji Island to two nearby islands, see Figure 17. The pipeline outside diameter is about $250 \mathrm{~mm}$, and the total of burial distance is about $7.5 \mathrm{~km}$. Except for some of the hard soil sections, the trencher successfully carried out the mission with the $0.8 \mathrm{~m}$ of average burial depth.

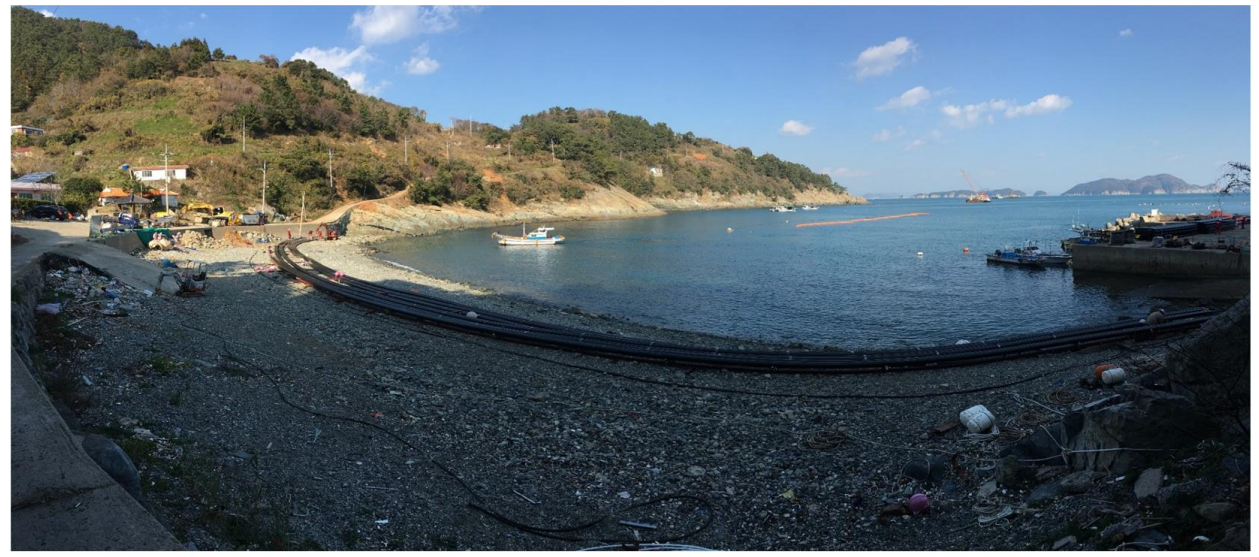

(a) Yogji Island construction site.

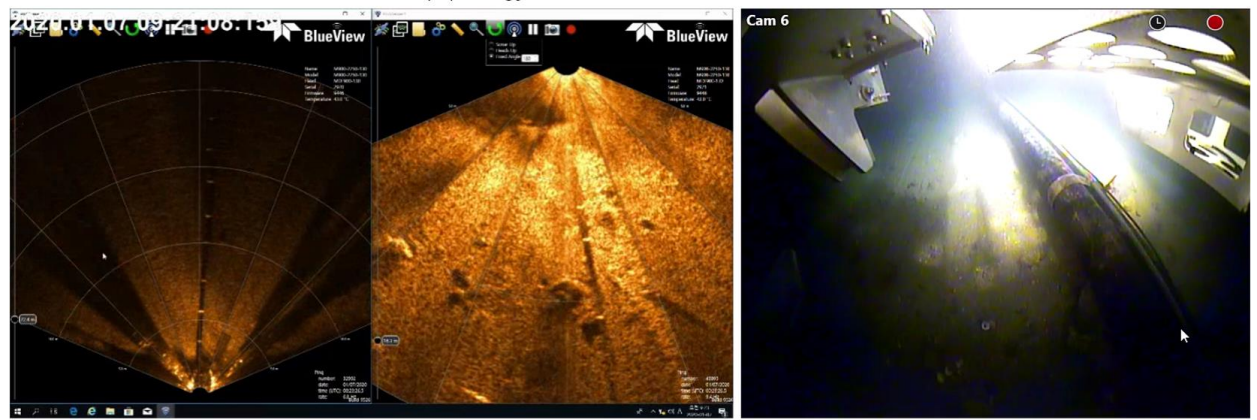

(b) Subsea water pipeline.

Figure 17. Subsea water pipeline burial site. (a) Yogji Island construction site, (b) subsea water pipeline.

\section{Conclusions}

This paper has presented a water jet tool optimal design method for a $2500 \mathrm{~m}$ depthrated ROV trencher. Indeed, due to the variety of seafloor soil types, it is almost impossible to design a one-size-fits-all water jet device. Nonetheless, a series of design and analysis procedures including CFD simulations, laboratory tests with one nozzle, and ground field tests with a 1:6 scale water jet tool prototype have been carried out to derive appropriate tool design parameters. In October 2018, the finalized trencher successfully performed the final performance evaluation test in the $500 \mathrm{~m}$ depth East Sea area; and, in December 2019, the trencher was put into a construction site near Yogji Island and successfully carried out the subsea water pipeline burial mission with $0.8 \mathrm{~m}$ of average burial depth. It is also notable that the trencher has successfully carried out a subsea gas pipeline burial mission in 2020. This contract was ordered by Petro Vietnam GAS, a Vietnam petroleum company. In addition, this is the first case where the outcome product of an R\&D project funded by MOF (Ministry of Oceans and Fisheries in Republic of Korea) has ever been put into a construction site ordered by a foreign company.

Author Contributions: Conceptualization, J.-H.L. and M.-J.L.; methodology, J.-H.L. and M.-J.L.; software, H.K. and M.-G.K.; validation, J.-H.L., M.-J.L., H.K., M.-G.K., G.R.C.; formal analysis, J.H.L. and M.-J.L.; investigation, J.-H.L., H.K., M.-G.K.; resources, J.-H.L.; data curation, J.-H.L. and 
H.K.; writing-original draft preparation, J.-H.L.; writing—review and editing, J.-H.L.; visualization, J.-H.L.; supervision, J.-H.L.; project administration, J.-H.L.; funding acquisition, J.-H.L. All authors have read and agreed to the published version of the manuscript.

Funding: This research was funded by the Ministry of Oceans and Fisheries (MOF), and the Korea Institute of Marine Science \& Technology Promotion (KIMST), Republic of Korea, Grant No. PJT2019396.

Conflicts of Interest: The authors declare no conflict of interest.
Abbreviations
ROV Remotely Operated Vehicle
CFD Computational Fluid Dynamics
URI-T Underwater Robot Is-Trencher
RPM Revolutions per Minute

The following abbreviations are used in this manuscript:

\section{References}

1. Mole, P.; Featherstone, J.; Winter, S. Cable protection-Solutions through new installation and burial approaches. In Procreedings of the SubOptic 1997, San Francisco, CA, USA, 11-16 May 1997; pp. 34-39.

2. IP Subsea. Available online: http://www.ipsubsea.com/cutting-vs-jetting/ (accessed on 2 February 2021).

3. Li, J.H.; Kim, J.Y.; Lee, M.J.; Lee, W.S.; Kang, H.J.; Han, H.C.; Lee, J.W.; Kwak, H.H. Conceptual design of optimal thrust system for efficient cable burying of ROV trencher. In Procreedings of the MTS/IEEE Oceans, St. John's, NL, Canada, 14-19 September 2014.

4. Li, J.H.; Kim, J.T.; Lee, M.J.; Jee, S.C.; Kang, H.; Kim, M.K.; Kwak, H.W.; Kim, S.B.; Oh, T.W. Water Jetting Arm Optimal Design Consideration for a ROV Trencher. In Procreedings of the MTS/IEEE Oceans Genova 2015, Genoa, Italy, $18-21$ May 2015.

5. Perng, A.T.; Capart, H. Underwater sand bed erosion and internal jump formation by travelling plane jets. J. Fluid Mech. 2008, 595, 1-43. [CrossRef]

6. Vanden Berghe, J.V.; Capart, H.; Su, J.C.C. Induced Trenching Operations: Mechanisms Involved, OTC-19441. In Procreedings of the Offshore Technology Conference, Houston, TX, USA, 5-8 May 2008.

7. Vanden Berghe, J.V.; Pyrah, J.; Gooding, S.; Capart, H. Development of a jet trenching model in sand. In Book Chapter of Frontiers in Offshore Geotechnics II; White, G., Eds.; Taylor \& Francis Group: London, UK, 2011.

8. Dong, C.; Yu, G.; Zhang, H.; Zhang, M. Scouring by submerged steady water jet vertically impinging on a cohesive bed. Ocean Eng. 2020, 196, 106781. [CrossRef]

9. Liang, D.; Zhao, X.; Martinelli, M. MPM simulations of the interaction between water jet and soil bed. Procedia Eng. 2017, 175, 242-249. [CrossRef]

10. Adamson, J.E.; Kolle, J.J. Development of a waterjetting cable burial system for a broad range of soils in up to 2500 meters of seawater. In Procreedings of the Underwater Intervention '95, Houston, TX, USA, 27-29 September 1995.

11. Crow, S.C. A Theory of Hydraulic Rock Cutting. Int. J. Rock Mech. Min. Sci. Geomech. Abstr. 1973, 10, 567-584. [CrossRef]

12. Cho, G.R.; Lee, M.J.; Kang, H.; Ki, G.; Kim, M.G.; Li, J.H. Evaluation of Underwater Cable Burying ROV through Sea Trial at East Sea. In Procreedings of the IFAC World Congress 2020, Berlin, Germany, 12-17 July 2020.

13. KT Submarine. Available online: http:/ / www.ktsubmarine.co.kr/download/brochure_e/T800.pdf (accessed on December 2013).

14. ANSYS CFX. Release 16.0; ANSYS Ltd.: Hongkong, 2015.

15. Newman, J.N. Marine Hydrodynamics; The MIT Press: Cambridge, MA, USA; London, UK, 1977; pp. 3-5.

16. Heller, V. Self-similarity and Reynolds number invariance in Froude modeling. J. Hydraulic Res 2016, 55, 293-309. [CrossRef]

17. Sverre, S. General Modelling and Scaling Laws, Tmr7 Experimental Lectures in Marine Hydrodynamics-Lecture in Week 34; NTNU, Institutt for Marin Teknikk: Trondheim, Norway, 2015.

18. ANSYS Manual; ANSYS Ltd.: Hongkong, 2015.

19. Wiki, C. Scaling Issues in Hydraulic Modelling. 2020. Available online: http://www.coastalwiki.org/wiki/Scaling_Issues_in_ Hydraulic_Modelling (accessed on 30 June 2015). 